\title{
Prácticas de sociabilidad en la modernización de Bayamo entre 1880-1930
}

\author{
Dayami Rodríguez López ${ }^{*}$ \\ Universidad de La Habana/CNC
}

\begin{abstract}
Resumen
La modernización, como proceso de transformaciones económicas, sociales y urbanas asociados al nacimiento del capitalismo, incluye una diversidad de factores entre ellos los de tipo social. Uno de ellos es la sociabilidad, la cual asume un lugar significativo en la transmisión y difusión de la modernidad en tanto deviene vehículo esencial para comprender las complejas urdimbres culturales entre los sujetos históricos en determinadas épocas y contextos históricos. A pesar de la importancia de los espacios de sociabilidad en la evolución de las ciudades y de la vida pública en Cuba, aún existen ausencias en las miradas historiográficas de las regiones y localidades del territorio insular. Entre esas localidades se encuentra Bayamo, segunda villa cubana fundada en 1513, ubicada en la región oriental de Cuba. Atendiendo a ello el presente texto se interesa por reconstruir una imagen de Bayamo desde una mirada a la evolución que experimentan algunos ámbitos de sociabilidad durante el período de los finales del siglo XIX y las tres primeras décadas del XX.
\end{abstract}

\section{Palabras claves}

Cuba, Bayamo, modernidad, sociabilidad, asociaciones

\begin{abstract}
The modernization, as a process of economic, social and urban transformation associated with the birth of capitalism, includes a variety of factors among them the social type. One of them is the sociability, which assumes a significant place in the transmission and spread of modernity as it becomes essential vehicle to understand the complex cultural warps between historical subjects in certain times and historical contexts. Despite the importance of sociability spaces in the evolution of cities and public life in Cuba, there are even absences in historiographic views of regions and towns of the island territory. These locations include Bayamo, second Cuban village founded in 1513, located in the eastern region of Cuba. Taking into account all these the present text is interested in reconstruct an image of Bayamo from a view at the evolution experienced by some areas of sociability during the period from the end of the 19th century and the first three decades of the 20th
\end{abstract}

\section{Keywords}

Cuba, Bayamo, modernity, sociability, associations

\footnotetext{
* Doctoranda en la Universidad de La Habana, Cuba. Investigadora de la Casa de la Nacionalidad Cubana en Bayamo
}

Esta obra está sujeta a la Licencia Reconocimiento-NoComercial-Compartirlgual 4.0 Internacional de Creative Commons. http://creativecommons.org/licenses/by-nc-sa/4.0/ 


\section{Introducción}

La modernización, asociada al nacimiento del capitalismo, incluye una diversidad de factores de orden económico, social y urbano, entre los cuales puede mencionarse la industrialización, el incremento de la movilidad social y la diferenciación clasista. Paralelamente da paso a la secularización, a la expansión de los medios de comunicación y las posibilidades de participación política. ${ }^{1}$ Si bien estos componentes adquieren notable trascendencia, no pueden aislarse de otros que ofrecen "un tamiz más fino para identificar los dispositivos que operan concreta y vitalmente como soportes de transmisión y difusión de la modernidad", entre los cuales pueden ubicarse los estilos de sociabilidad y con ello, el desarrollo de espacios culturales urbanos, dígase cafés, tabernas, sociedades eruditas, salones, clubes de debate, asambleas, teatros, galerías y salas de concierto. ${ }^{2}$

Desde esta perspectiva es posible escudriñar en los caminos de la evolución de la sociedad cubana hacia la modernidad, a partir de una serie de transformaciones en la economía, la política y la vida social que irrumpen por la década de 1880 y alcanzan su máxima expresión en el siglo XX. En tal sentido resultan interesantes los cambios legales introducidos durante esa década por las leyes de asociaciones y reuniones públicas. El amplio compendio legislativo, de conjunto con otras normativas de similares pretensiones, modificó "el marco jurídico de la vida social, como parte de un proceso culminante en la constitución de la República cubana, la cual -no obstante las evidentes limitaciones de sus facultades soberanas y otras distorsiones funcionales- poseía los atributos políticos e institucionales propios de un Estado Moderno"3

Uno de los aspectos más dinámicos en esta estela de transformaciones estuvo en la reorganización de la sociedad civil, marcada por la inserción de los miembros de las capas populares en la esfera pública ${ }^{4}$. De hecho se asiste a una ampliación de

\footnotetext{
${ }^{1}$ Para ampliar véase: José Joaquín Brunner. "Modernidad: centro y periferia. Claves de lectura”, en Estudios públicos, no. 83, Chile, 2001, p. 247. Disponible enwww.cepchile.cl/dms/archivo 1826 560/rev83 brunner.pdf, fecha de acceso 12 de octubre de 2012.

${ }^{2}$ Porter. R. (2000): "The creation of the modern world", Londres/ Nueva York., W.W. Norton and company, Apud. José Joaquín Brunner, Ob. cit., p. 247. Brunner también considera importante el establecimiento de hospitales, prisiones, escuelas y fábricas, la difusión del periódico y la aceleración de las comunicaciones, el comportamiento de los consumidores y el marketing de nuevos productos y servicios culturales.

3 Oscar Zanetti Lecuona: Comercio y Poder. Relaciones cubano-hispano-norteamericanas en torno al 98. La Habana, Fondo Editorial Casa de las Américas, 1998, pp 294-295. Las limitaciones en la soberanía apuntadas por el autor se refieren a las condiciones de neocolonialismo en que surge la República cubana bajo la dominación de Estaos Unidos entre 1902 y 1959.

${ }^{4}$ Sobre este asunto la historiografía cubana ha tenido notables avances a partir del interés por la vida social de los sujetos populares. Dentro de ese campo se ha prestado más asunto a los estudio del sector de los negros y mulatos dado el mestizaje que caracteriza nuestra sociedad. Asimismo hay autores como María del Carmen Barcia que no dejan de reconocer la existencia de ciertas elites dentro de esos sectores. Para ampliar sobre este particular véase de esa autora: "La sociabilidad de
} 


\section{Dayami Rodríguez López}

las formas y espacios de sociabilidad, destacándose la diversidad de propósitos, dígase benéficos, comerciales, religiosos, deportivos, musicales, fraternales, laborales, de instrucción y recreo asumidos por las instituciones llamadas a integrar los múltiples grupos de la sociedad cubana.

El estudio de dichas entidades ofrece claves para comprender la complejidad que impregnan las relaciones sociales al proceso de la modernidad. A pesar de la importancia de estos espacios de relación en la evolución de las ciudades y de la vida pública en Cuba, aún existen ausencias en las regiones y localidades del territorio insular. Entre esas localidades se ubica Bayamo, segunda villa cubana fundada en 1513, ubicada en la región oriental de la Isla.

Dentro de las producciones historiográficas sobre ese territorio persisten vacíos en lo referido al análisis de las prácticas de sociabilidad como componentes activos del camino hacia la modernidad. ${ }^{5}$ Atendiendo a ello las siguientes páginas se interesan por reconstruir una imagen de Bayamo desde una mirada a la evolución que experimentan diversos ámbitos de sociabilidad, entre los cuales se destaca el de las sociedades recreativas, durante el período de los finales del siglo XIX y las tres primeras décadas del XX.

En estos complejos sitios se manifestó lo que Maurice Agulhon ha designado como colectivización de la vida, o sea, el proceso mediante el cual un grupo de prácticas sociales, en materia de ocio, de lectura de periódicos, de juegos, pasaron de privados a un uso más colectivo, llegando a incluir a algunos miembros de los sectores populares. ${ }^{6}$ Sin embargo, este "uso colectivo" al que alude el académico francés, no hizo más que reforzar las encrucijadas modernas en que se insertaron los bayameses y deviene factor de relevancia para analizar los procesos que acontecen en las instituciones recreativas, donde aparejado a la supuesta apertura que propugnan para acceder a los beneficios de esa colectivización, persistieron

\footnotetext{
las capas populares en la conformación de una sociedad moderna (1880-1930)", en Colectivo de Autores: Historia y Memoria: Sociedad, cultura y vida cotidiana en Cuba 1878-1917. La Habana, Centro de Investigación y Desarrollo de la Cultura Cubana Juan Marinello, 2003; Capas Populares y Modernidad en Cuba (1878-1930). La Habana, Fundación Fernando Ortiz, 2005 y Los ilustres apellidos: negros en la Habana colonial. La Habana, Editorial Ciencias Sociales, 2009, 2da ed. Existe otro grupo de historiadores que se ha acercado a la historia obrera y económica. Para ampliar véase las sistematizaciones historiográficas de Barcia Zequeira: "El tema negro en la Historiografía cubana del siglo XX", en revista Del Caribe, (44), 2004, Santiago de Cuba. pp. 102-110; Ricardo Quiza Moreno: "Sujetos olvidados: los trabajadores en la historiografía cubana"; en Rolando Julio Resoli Medina (comp): La Historiografía en la Revolución cubana. Reflexiones a 50 años, La Habana, Editora Historia, Instituto de Historia de Cuba, 2010, pp. 313-347 y de Gloria García Rodríguez: "Los negros y mulatos en la sociedad colonial", Ibid, pp.297-306.

5 Los proyectos auspiciados por la Casa de la Nacionalidad Cubana, centro de investigaciones históricas radicado en Bayamo han preferido la etapa de la Colonia durante los siglos XVI- XIX y cuestiones de la vida económica y política más que la cultural. Actualmente se investiga sobre la Asociación Cívica de Bayamo (1943-1959) y sociedades benéficas. Para el caso de la vida obrera, pero no de sus asociaciones, se puede consultar: Liliana Alarcón Vázquez: "El movimiento obrero en la fábrica Nestlé", Granma Ciencia, no. 1, 2006, y de esta misma autora y Sonia Tornés Mendoza: "El movimiento obrero tabacalero en Bayamo, Granma Ciencia", no. 1, 2005.

${ }^{6}$ Agulhon, Maurice: "La modernidad de la institución: el café-círculo y la reunión entre hombres", en El Círculo Burgués. La sociabilidad en Francia, 1810-1848. Buenos Aires, Siglo XXI Editores, 2009, pp.100-101.
} 


\section{Prácticas de sociabilidad en la modernización de Bayamo}

estrictas limitaciones y exclusiones sociales, que reprodujeron a escala micro los códigos diferenciadores de la modernidad. Esas dicotomías fundamentan nuestro interés por utilizar aspectos más sensibles como las relaciones cotidianas entre los hombres en los espacios para la sociabilidad informal y formal ${ }^{7}$ para mostrar una arista de la modernidad bayamesa. Esta se hizo visible desde la expansión del tejido asociativo, de los espacios para la sociabilidad informal en estrecha conexión con cierta tendencia a la urbanización, al desarrollo de la prensa y la vida política en medio de un aumento demográfico y un paulatino ascenso de la actividad económica, con resultados más visibles hacia el siglo XX.

\section{1. Ámbitos de sociabilidad en la paradójica modernidad de Bayamo (1880- 1930)}

La sociabilidad y las relaciones inherentes a la misma devienen lente privilegiado para escribir sobre los procesos de modernización negado a ciudades que por sus pautas rurales no siguen los modelos de las grandes urbes. ${ }^{8}$ En ese ámbito se ubica la ciudad de Bayamo por la lejanía de La Habana, centro económico, político y cultural más importante del país durante el período de estudio y por su activa vinculación con los hechos de la "Guerra de los Diez Años" (1868-1878), primera contienda bélica contra España por la independencia cubana y de la revolución de 1895- 1898, que puso fin al dominio colonial español9.

La incidencia de los sucesos revolucionarios se hizo sentir sobre el devenir de la región, ${ }^{10}$ y la ciudad se colocó en desventaja con relación a otras zonas de la Isla.

\footnotetext{
${ }^{7}$ La división de los tipos de sociabilidad parte de las consideraciones teóricas de Maurice Agulhon quien concibe la sociabilidad como la aptitud de vivir en grupos y consolidarlos mediante la constitución de asociaciones voluntarias, pero que no deja de reconocer la existencia de formas de relación de corte más informal incluso hacia el interior de los espacios formales. Maurice Agulhon: Historia Vagabunda. Etnología y política en la Francia contemporánea. México, Instituto Mora, 1994 y El Círculo Burgués. La sociabilidad en Francia, 1810-1848.

8 Para ampliar puede consultar: Pilar Calvo Caballero: La Sociabilidad burguesa en Castilla y León siglo XIX y XX, un estado de la cuestión", Universidad de Valladolid, en revista IH, (20), España, 2000. Disponible en. http://dialnet.unirioja.es/servlet/oaiart?codigo=66474, fecha de acceso 10 de febrero de 2011.pp. 226-227.

9 Para ampliar sobre el proceso independentista cubano existe un número significativo de obras pues la historiografía nacional ha prestado mucho interés a la temática dada la trascendencia de esos acontecimientos para el proceso de formación nacional. Entre los textos que ofrecen una panorámica general del fenómeno se encuentra el publicado por el Instituto de Historia de Cuba: Historia de Cuba. Las Luchas por la independencia nacional y las transformaciones estructurales 1868- 1898. La Habana,, Editorial Félix Varela, 2006, t II, 2da parte. No obstante existen otros aportes que a grandes rasgos se esbozan en el texto de Mercedes García: "La historiografía colonial cubana"; en, Rolando Julio Resoli Medina (comp): La Historiografía en la Revolución cubana. Reflexiones a 50 años, La Habana, Editora Historia, Instituto de Historia de Cuba, 2010, pp 66-86 10 Durante la guerra de los Diez Años, el 12 de enero de 1869 los bayameses decidieron prender fuego a sus casas para evitar la toma de la ciudad por las tropas españolas. Este hecho a pesar de su sentido patriótico tuvo una notable incidencia sobre la arquitectura, el urbanismo y la vida social de Bayamo. Para ampliar sobre efectos de la guerra véase: Idelmis Mari Aguilera: Fuego y Ocaso. Bayamo, Ediciones Bayamo, 2005, Diurkis Madrigal León: La familia y la guerra. Bayamo, Ediciones Bayamo, 2005, Rafael Rodríguez Ramos: San Salvador de Bayamo: Arquitectura y urbanismo en la
} 


\section{Dayami Rodríguez López}

La economía se vio afectada por la disminución de los ingresos por conceptos de industria y comercio y ganado, por la reducción del número de contribuyentes y la escasez de transporte. Paralelamente, decrecieron las tasas demográficas y la vida urbana mostró cierta decadencia desde el punto de vista arquitectónico y social. Sin embargo a partir de la década de 1880, se distingue cierta inserción de la ciudad en un paulatino proceso de cambios, el cual tendrá en la sociabilidad una de sus aristas más visibles. Las vinculaciones entre los residentes en la segunda villa cubana en pos de compartir un espacio para socorrerse, jugar, leer, recrearse y defender posiciones políticas, fueron esencialmente los catalizadores del dinamismo de Bayamo en el último tercio del siglo XIX.

De tal suerte puede establecerse un primer momento en la evolución del proceso modernizador de Bayamo, marcado esencialmente por la introducción en la década de 1880 de las normativas jurídicas que regularon el derecho de reunión y asociación. Ello propició el ordenamiento de las instituciones existentes en la jurisdicción, previo a la legislación y una mayor vigilancia sobre determinadas prácticas como las celebraciones de fiestas bailables, tocatas de órganos, las procesiones cívicas y la creación de partidos políticos. Concluye en 1910 cuando se inaugura el segundo ciclo modernizador con la llegada del ferrocarril, lo cual propició la comunicación con regiones de importancia económica, un mayor surtido de insumos, el incremento de los comercios y el fomento de fincas rurales. A la par, el ordenamiento citadino se comenzó a reconfigurar con la construcción de nuevas edificaciones, la fundación de instituciones de créditos, el auge de la movilidad poblacional, la aparición de nuevas prácticas de sociabilidad y el aumento de la circulación periodística.

Cerramos esta etapa en la década de 1930 cuando ocurre otro acontecimiento de importancia económica que abrió nuevos horizontes para Bayamo: la inauguración de la fábrica para condensar leche "Nestlé", alrededor de la cual también se constituyeron determinadas instituciones. A la par se comienzan a reajustar los patrones de sociabilidad dado por el cierre de un grupo de entidades por decretos del gobierno y la apertura de otras, por los desgajamientos dentro de las entidades recreativas. Todo ello provocó una mayor disección de los grupos y sectores de la sociedad bayamesa, cada vez más propensos a buscar en la asociación formas de legitimación. Paralelamente se reafirmó el proceso de expansión y diversificación de las sociedades hacia los barrios rurales en ascenso desde la década del 1920.

Retomando la primera etapa de la modernización se ha de notar que el despertar de las décadas del 1880 y 1890 también estuvo marcado por las intenciones del Ayuntamiento colonial de mejorar el ornato e higiene públicos, de rotular calles y numerar casas, de mejorar la Plaza Cristóbal Colón (luego Plaza de la Revolución), de extinguir los cercados e impulsar nuevas construcciones

colonia (1513-1898), multimedia; Bayamo, ediciones Bayamo, 2011; de Susana Martínez Sánchez y José Alberto Zayas Pérez: "Crecimiento urbanístico de Bayamo", en La historia en la palabra, vol. V, pp. 113-123. 
domésticas. Si bien hubo propuestas para fomentar nuevas escuelas y construir una plaza de mercado, en la mayoría de los casos estas se vieron frustradas por la escasez de recursos del Ayuntamiento y la falta de iniciativas privadas.

En cuanto a las expresiones de sociabilidad en ese período hubo un incremento de los bailes públicos, se inscribieron algunos billares, cafés, cantinas, fondas, barberías, zapaterías, librerías, bodegas, vendutas y panaderías; ubicadas, por lo general, en la Plaza de la Revolución y otras arterias de importancia. Por su parte, el ámbito de los espacios formales para la sociabilidad también se reconfiguró ofreciendo acceso a la institucionalización de un grupo de prácticas asociativas de las elites en el modo de vida de los sujetos populares. De esa manera se produjo una ruptura con la típica tendencia a la asociación de los sectores de las elites en sociedades filarmónicas y casinos españoles ${ }^{11}$. Esa inclinación de los miembros de las capas populares se denota como una característica distintiva del período y se manifestó en hechos como las solicitudes de algunos artesanos para fundar asociaciones recreativas, de socorros mutuos ${ }^{12} y$ gremios para congregar albañiles, zapateros, carpinteros, sastres, herreros, barberos, hojalateros y talabarteros. Cuando se estableció de forma permanente en la Isla la Ley de Asociaciones (1888), ya se habían instalado cinco de las seis instituciones bayamesas que oficialmente se inscribieron ante el gobierno hasta finales del siglo XIX. De tal suerte la citada ley estableció un mayor control por parte de las instancias gubernamentales sobre las asociaciones existentes, las cuales debieron reordenarse y comenzar a enviar una serie de informaciones de acuerdo a los requisitos exigidos por la recién dictada normativa.

Los propósitos instructivos, junto al del socorro mutuo y el recreo, predominaron entre los intereses de los congregados en las seis instituciones existentes por aquella época en la ciudad. ${ }^{13}$ En ese contexto, la estructuración del

\footnotetext{
${ }^{11}$ Para ampliar sobre las sociedades filarmónicas véase: Mario Cobas Sanz: "Bayamo y la sociedad filarmónica en el siglo XIX", en Ventana Sur, no. 6. Del mismo autor: "La Sociedad Filarmónica y el vanguardismo político-cultural en Bayamo 1840-1870", en revista Santiago, no. 127, enero-abril, 2011, Santiago de Cuba. Sobre el Casino Español de Bayamo, véase: Dayami Rodríguez López: "Españoles en Bayamo: Miradas desde las sociabilidades", en Jose Manuel Azcona e Israel Escalona: Cuba y España. Procesos migratorios e impronta perdurable. España, Editorial Dykinson, 2014, pp 125-145. La temática de los casinos españoles en otras regiones puede ampliarse en: María del Carmen Barcia: Elites y grupos de presión en Cuba(1868-1878). La Habana, Editorial de Ciencias Sociales, 1998. Áurea Matilde Fernández: España y Cuba 1868 -1898. Revolución burguesa y relaciones coloniales. La Habana, Editorial de Ciencias Sociales, 1988; Mayela Vázquez Díaz: "Legado social hispano en Guantánamo: El Casino Español", en Cuba y España...,pp 145-161 y sobre las filarmónicas: Edita María Caveda Romaní: Las sociedades filármonicas habaneras (1824-1844). La Habana, Instituto Cubano de investigación cultural Juan Marinello, 2009.

${ }^{12}$ La Unión fue la primera de las iniciativas asociativas de los negros y mulatos en 1882.A ella le siguieron otras como el Señor de la Salud (1886), de socorros y en 1890 El Progreso Bayamés, también de artesanos. Ello no fue óbice para la creación de asociaciones como La Benéfica (1884) y Licenciados del Ejército (1887), diseñadas por blancos, tanto españoles como cubanos, las cuales coexistieron con el Casino Español (1871).

${ }^{13}$ En la ciudad no existieron por esos años sociedades anónimas, al igual que en otras regiones del Oriente de Cuba entre ellas Baracoa, Sagua de Tánamo, Holguín, Alto Songo, Victoria de Tunas, Manzanillo. Se consigan solo en Gibara, Guantánamo, Mayarí y Cobre. En: Archivo Histórico Provincial de Santiago de Cuba, en lo adelante, AHPSC: Fondo Gobierno Provincial, FGP, leg. 248911/2,
} 


\section{Dayami Rodríguez López}

campo asociativo fue resultado de una realidad marcada por las secuelas de las guerras, que motivó la escasa difusión de instituciones. No obstante, no se puede restar trascendencia a las inscritas pues dieron cuenta de la eficacia de las formas colectivas de solidaridad para resolver problemas cotidianos como el auxilio ante las enfermedades, la asistencia sanitaria, la muerte, la educación y el recreo. Paralelamente el interés de los negros y mulatos, reunidos bajo el signo de la "unión", "el progreso y la instrucción", los hizo ponderar cuestiones relativas al estudio de materias científicas y sociales, pues la educación, en tanto vía para elevar su nivel cultural y social, los conduciría al progreso intelectual, moral, a la verdadera libertad y colocándolos en afinidad con la vida moderna.

Estos objetivos no estuvieron al margen del deseo de los bayameses de otorgarle un nuevo sentido a la vida social y a la identidad cultural y local. De tal suerte, estas relaciones tejidas en torno a espacios formales o informales, privados o públicos, desde finales del siglo XIX mostraron una mayor participación ciudadana y sentaron las bases para los inicios de la República, instaurada oficialmente en 20 de mayo de $1902^{14}$. En los inicios de ese nuevo período no se visualizan muchos cambios en la infraestructura heredada de la etapa colonial. La recién inaugurada época se caracterizó por la vigencia de una especie de modernidad nostálgica, derivada de la persistente conexión entre los remanentes del heroico pasado vivido por los bayameses en el contexto de las gestas anticoloniales - presidido por la epopeya asociada al incendio del pueblo- y las aspiraciones de progreso y cambio imperantes en la Isla. De modo que el sello de modernidad de Bayamo estuvo bañado por cierta pátina arraigada a símbolos de una historia patriótica donde sus moradores habían sido protagonistas.

Esta mezcla de historia y renovación signó el discurso de los alcaldes de la primera década republicana, los señores Manuel Planas Rodríguez del Rey (18981902), (1909-1912) y Francisco Estrada Mariño (1902-1908) y también se extendió a las formas de asociarse, como se advertirá en la creación del Círculo Bayamés en 1899 y la Colonia Española en 1909. En tal sentido el primero de los alcaldes, en una comunicación al Presidente de la República para referirse al abandono y a la necesaria transformación de la ciudad, fechada en 1909, reclamaba por el olvido de la altas instancias del gobierno republicano, a pesar de ser Bayamo "la ciudad mártir y heroica", pero con optimismo también declaraba sus aspiraciones de "mejores tiempos" para los destinos de Bayamo. ${ }^{15}$

exp. 3, 1886. No obstante, se ha constatado la legalización ante notarios en el año 1889 de las sociedades mercantiles, colectiva agrícola "Vallés Hermanos y Compañía" para la explotación del Ingenio Central de elaborar azúcar "Sofía” y de la compañía mercantil regular colectiva, razón social "Mera, Pinedo y Cía." para la compra venta y fabricación de materia prima y artículos concernientes a tenería. Casa de la Nacionalidad Cubana, en lo adelante CNC. Fondo Protocolos Notariales 18801905.

${ }^{14}$ En la historia de Cuba se conoce como República, al período que se inicia el 20 de mayo de 1902 en condiciones neocoloniales bajo la égida de Estados Unidos- y culmina en enero de 1959 cuando Triunfa la revolución cubana.

${ }^{15}$ Los "mejores tiempos" exigían la solución de problemas vinculados a la higienización y ornato público, la instrucción y el fomento agrícola. Entre los más necesarios podrían señalarse los 
En lo que respecta a las instituciones aludidas El Círculo... devino centro donde las dirigencias mambisas locales ensalzaron su lugar en el imaginario político de la época, desde los valores simbólicos adjudicados por su participación en las guerras. A la vez sirvió para generar una simbiosis entre un selecto grupo de españoles y cubanos, sello del reacomodo de la sociedad poscolonial y resultado de la hibridez étnica generada por el advenimiento de la República.

En este contexto caracterizado por una creciente inmigración española, la simbiosis inicial del Círculo... debió reajustarse ante la creación de la Colonia Española en el año 1909, justo en el momento de consolidación de dicha colonia de inmigrantes en la ciudad. ${ }^{16}$ La instalación de la Colonia..., al decir de sus auspiciadores resumía

la satisfacción concreta del grande ideal que mueve á todos sin distinciones de ninguna especie en esta comarca. Españoles y Cubanos, sin enconos de ninguna clase, sin suspicacias, dudas ni temores, han levantado muy alta la bandera, no de España ni de Cuba [...] sinó (sic) la de fraternal unión y concordia entre todos los elementos. ${ }^{17}$

Tanto los cubanos como los españoles intentaron borrar la memoria de treinta años de guerra estrechando lazos de amistad y solidaridad en estas instituciones, pero el ideal de unión de cubanos e hispanos en la Colonia Española fue en sí contradictorio, reflejando la propia complejidad del proceso de construcción de la nación cubana.

Las nuevas perspectivas abiertas en el campo de la sociabilidad a partir de la década de 1910 también se comienzan a hacer visibles para el entorno urbano de Bayamo desde las exigencia de reconstrucción de solares yermos de la Plaza de la Revolución,-espacio público más importante de la ciudad-y en otras calles principales, con la ampliación del Término Municipal con nuevos barrios y un crecimiento demográfico, así como la extensión de los servicios de la telefonía, el alumbrado y el acueducto. ${ }^{18}$ Estos avances, reseñados por los diarios locales $E l$

relacionados con el hospital, cementerio, la plaza de mercado, la construcción de puentes, los tramos de carretera, el aumento de las escuelas públicas en barrios rurales, una estación agronómica, una escuela de agricultura y una sucursal del Banco Hipotecario. AHPG: Libro de Actas Capitulares, no. 13, sesión 1ro de noviembre de 1909, acuerdo no. 2, p. 259 y AHPG: Fondo Gobierno municipal Neocolonia, en lo adelante FGMN, leg. 69. exp. 2056, 1909.

${ }^{16} \mathrm{El}$ análisis de las cifras poblacionales así lo refiere, pues el número de españoles superaba la de otras nacionalidades asentadas en la zona y registró un considerable crecimiento entre 1899 y 1919. En 1911 existían 480 españoles en Bayamo. Registro de Población del Término Municipal de Bayamo (1911).CNC: Fondo República, leg. 111, exp.1052. De acuerdo con los censos de la República, el comportamiento de las cifras sobre la inmigración hispana en Bayamo es el siguiente: 1899: Cuba 20 941, España, 195, en 1907: Cuba 26 143, España, 264, en 1919: Cuba 44327, España 556, Informe del Censo de Cuba 1899, p. 230; Censo de la República de Cuba. Bajo la Administración provisional de los Estados Unidos, 1907. Oficina del censo de los Estados Unidos 1908, p.339, Censo de la República de Cuba. 1919, p. 430.

${ }^{17}$ Memoria Anual de la Colonia Española, 1910, Bayamo, Imprenta el Oriente, 1910, p. 18.

${ }^{18}$ Los nuevos barrios se habían comenzado a establecer al finalizar la década de 1910 asociados a zonas favorecidas por la instalación del ferrocarril y otras vías de comunicación y a nuevas 


\section{Dayami Rodríguez López}

Fénix y La Regeneración en notas editoriales tituladas “¡Ave Bayamo!”(1909) y “El despertar de un pueblo" (1913), fueron anclados a un discurso de recordación a la época heroica de la ciudad, para sobredimensionar los esfuerzos de los bayameses al resurgir de las cenizas dejadas por el incendio y dotar a la urbe de ciertos signos de progreso.

También se asistió a una gradual expansión de los medios de comunicación con un saldo favorable para la opinión pública, sobre todo a partir de 1906 con la circulación de El Bayamés, al parecer el primer intento periodístico del siglo XX. ${ }^{19}$ El despertar de la prensa dio cuenta del civismo y las ansias de progreso, convirtiéndose en la antesala de nuevos y mejores tiempos. La defensa de un proyecto de modernidad de los bayameses a inicios del siglo XX, los convidó a buscar desde la prensa un espacio propio para el debate, la confrontación y por ende, para la dinamización de la sociedad.

El perímetro urbano de Bayamo integrado por los barrios San Juan y el Cristo, desde finales del siglo XIX se fue reorganizando para convertirse en el espacio geográfico de preferencia para el auge de los espacios para las prácticas de sociabilidad. Sin embargo, el Cristo, al ser el menos afectado por el incendio ${ }^{20}$ se señalizó como el principal dentro del área urbana de Bayamo. En el entorno del mismo se comenzó a desarrollar la actividad del pequeño comercio, se establecen centros recreativos, benéficos, partidos políticos y se ubicaron sitios públicos como la plaza de la revolución, la plaza del Himno Nacional, la plaza Santo Domingo y la del Cristo.

La plaza de la revolución, ampliada y modificada en virtud de las necesidades

producciones agro-ganaderas. Así aparecen Cayamas, Julia y Arroyo Blanco de Cautillo en 1916. Libro de Actas Capitulares, no. 16, sesión 4 de diciembre de 1916, p.92. Para ampliar sobre las variables demográficas veáse: Diurkis Madrigal León: "Bayamo 1774-2002. El lenguaje de las cifras a través del tiempo", en La historia en la palabra, vol. V, pp. 103-112. Desde la década del 90 del siglo XIX, se percibe el interés de una de las casas comerciales de la época por instalar líneas telefónicas entre sus fincas y las casas de comercio de la ciudad. Esta práctica continuó en ascenso en el nuevo siglo y ya para 1912 se cursan comunicaciones entre el administrador general de la Cuban Telephone Company de la Habana y el Alcalde de Bayamo, solicitando autorización para ubicar postes redondos de madera con el fin de instalar el servicio de larga distancia y el local para así unir a los pueblos con la capital. AHPG: FGMN, leg. 79, exp. 2499. Para 1914 se anuncia la llegada del personal de la United Construction and Supply Co, encargado de la instalación del servicio telefónico local. AHPG: FGMN, leg. 84, exp. 2670. El acueducto se inauguró en 1904 y el alumbrado eléctrico en 1908.

19 En la década del 80 del siglo XIX en Bayamo se publicaban los diarios La Aurora de Bayamo (1882)yLa Caridad (1886) La Libertad (1887).Pero al parecer estas publicaciones no tuvieron continuidad al siglo XX, pues entre1904 y 1905 no consignaba la publicación de ningún diario, a diferencia del resto de las ciudades del Oriente, con una amplia circulación periodística. Luego de salir a la luz pública El Bayamés, entraron en el juego de la opinión La Verdad, La Voz del Pueblo, El Fénix, La Regeneración, El Combate, La Opinión y El Paladín, Bayamo, El Heraldo de Bayamo, El Imparcial y la revista Hojas y Flores, por sólo citar algunos de los aparecidos en estas dos primeras décadas. También en 1915, el periódico Bayamo anunciaba la salida del primer número de la revista educacional y literaria La Edad de Oro, bajo la dirección y administración del maestro de profesión Carlos Costa Aliaga. Bayamo, no. 627, 2 de agosto, 1915.

20 En la actualidad el arquitecto Rafael Rodríguez Ramos está ejecutando la investigación: Mapificación del Incendio de la ciudad, 1869.Con la misma se pretende graficar los efectos del incendio de la ciudad y ofrecer una visión de la ciudad antes y después de ese momento histórico. 


\section{Prácticas de sociabilidad en la modernización de Bayamo}

recreativas, adquirió notable relevancia. En la misma se escenificaron las retretas de la Banda municipal, el recibimiento de personalidades de la vida pública y social de la nación y fue sede de las instituciones de recreo más significativas, pero a la vez en sus alrededores se establecieron cafés, hoteles, cines- teatros, restaurantes, cafeterías, tiendas para ventas de accesorios de oficina y una imprenta.

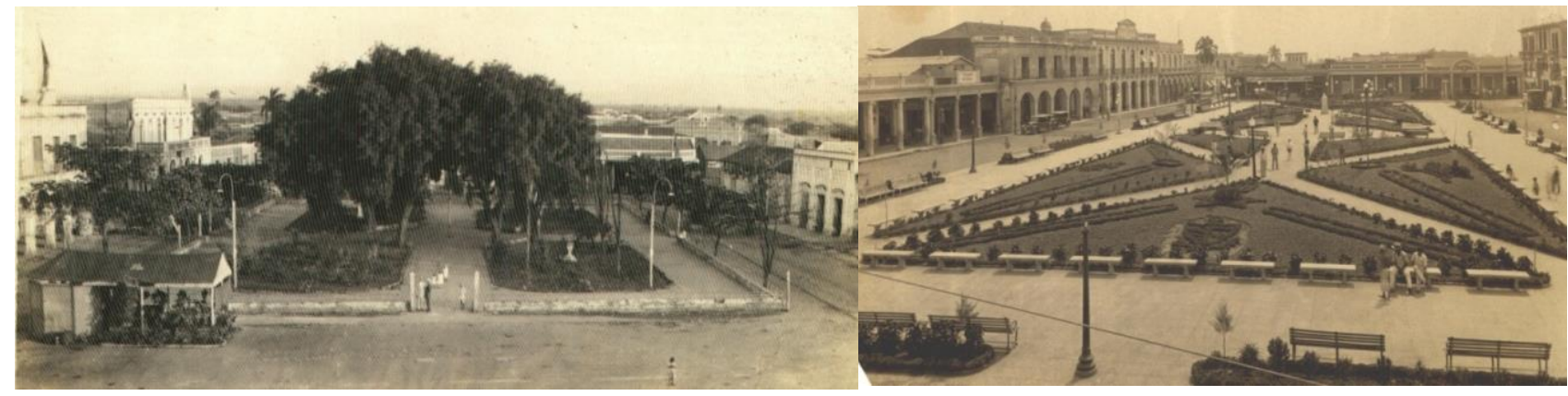

Plaza de la Revolución de Bayamo, inicios del siglo XX.

Plaza de la Revolución, década de 1930

Por su parte la actividad comercial mixta, escenario para las relaciones informales, se desarrolló indistintamente en una u otra zona del área urbana, esencialmente en arterias como José A. Saco, General Calixto García, José Martí, Carlos Manuel de Céspedes. No obstante, estas últimas, junto a la calle Donato Mármol fueron los lugares preferidos para el establecimiento de las consultas y bufetes de los profesionales, aun cuando se instalan otros en General García y Saco. $^{21}$

Esta situación hará de Bayamo una zona caracterizada por la concentración en sus calles principales de áreas comerciales, administrativas, judiciales y de servicios, así como de diversos espacios para el intercambio social. Todos estos sitios coexistieron con el área residencial, donde curiosamente las clases dominantes prefirieron, al menos por esa etapa, arraigarse y no abandonar el antiguo centro urbano para constituir una zona segregada. A pesar de la preponderancia del Cristo, puede estimarse que ambos barrios fungieron como centros receptores de la vida social donde los comerciantes y hacendados residentes allí y en zonas rurales cercanas, asistían a compartir sus ratos libres. ${ }^{22}$

${ }^{21}$ La diversidad del área comercial nos induce a establecer una denominación más abarcadora que
denominamos comercio mixto y que incluye joyerías, sombrererías, relojerías, peleterías, tiendas
de tejidos, locerías y ferreterías, camiserías y sastrerías, barberías, cafés, depósitos para ventas de
máquinas de coser Singer, de autos, implementos agrícolas y otros sitios del comercio local.
${ }^{22}$ El café, un dinámico espacio de sociabilidad se tipificó por su marcado ascenso y una expansión
geográfica, por ejemplo, en el Directorio comercial de 1907-1908 solo se consignaba uno, pero en
1927 aparece un total de veinte, algunos con billares. Entre sus ubicaciones se encontraban en la
Plaza de la Revolución el "Plus Ultra" de José Álvarez; el "Continental" de Fernández y Mainet; en
Saco y Pío Rosado el Café "Unión", de José M. Alonso; en Parada y Paradero el Café "Pasaje" de
Antonio Valin; en General García, "Diez de Octubre" de Cárdenas y Catasús; "El Zuizo" de Antonio
Fernández, "El Gato Negro" de Ricardo Fernández; "El Comercio", de Gómez y Sanjuría, "El amor a 


\section{Dayami Rodríguez López}
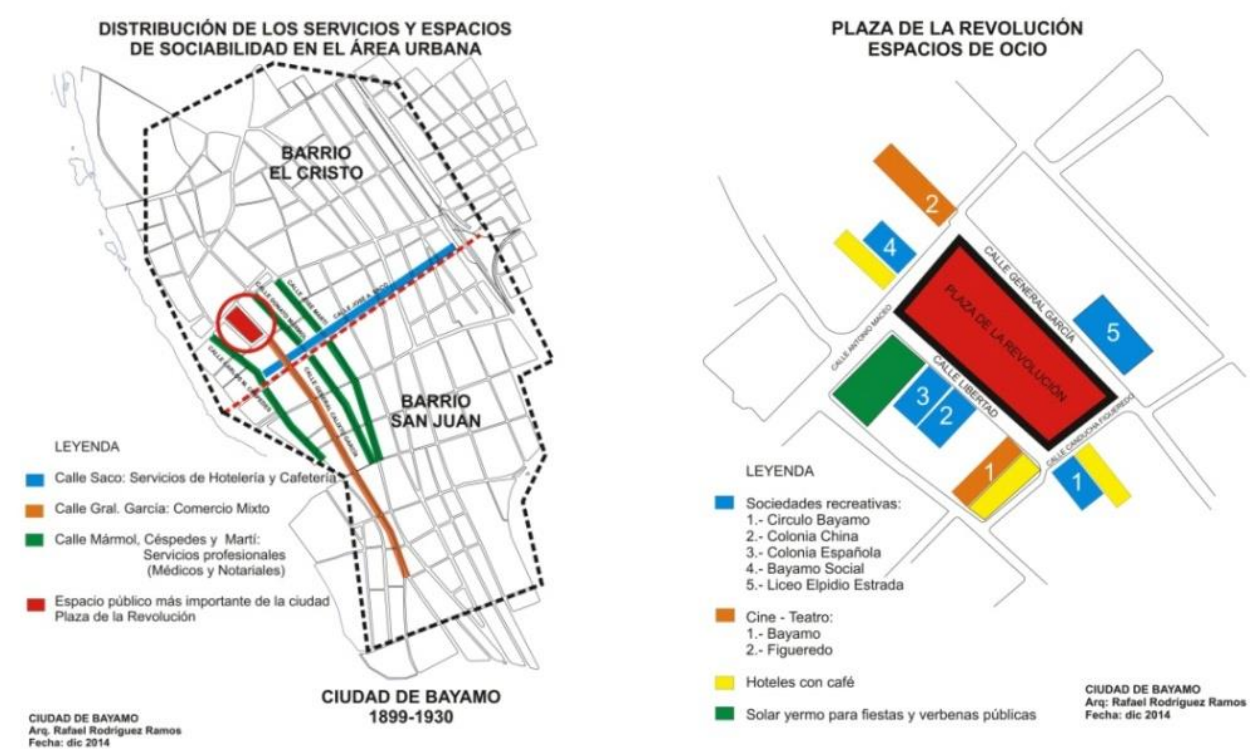

Si bien hubo un dinamismo asociativo en la zona urbana de Bayamo, en la rural se expresaron algunos cambios, entre ellos la constitución de asociaciones, sobre todo hacia donde había una activa vida económica como Veguita y Guisa. ${ }^{23}$ En estas circunstancias se denotará una diferencia con el último período del siglo XIX y los diez primeros años del XX, dado la expansión de un mayor número de asociaciones a partir de 1920 y en los años subsiguientes por toda la geografía bayamesa.

Unido a esta realidad, las calles y plazas se hicieron testigos de fiestas, verbenas, desfiles cívico-políticos, retretas, procesiones religiosas, corridas de cinta y a caballo. Una de ellas, las Fiestas de Reyes, auspiciada desde la época colonial por la hermandad de la Virgen del Rosario, generó gran movilidad. Las celebraciones organizadas por un comité gestor ?integrado por sociedades, casas comerciales y particulares? iniciaban el día 31 de diciembre y concluían el 7 de enero. Entre los momentos más significativos de esta festividad se encontraban los juegos tradicionales, las lidias de gallo, los bailes en sociedades y las ventas de

Bayamo”, de Sánchez y Valcárcel, en la calle Mármol, el café de Enrique Coltet; en Parada y San Roque: "La Flor de Cuba", en Parada, Café Tornos "Hotel Pasaje", de Francisco Sosa. Los CafésRestaurant se ubicaron en los hoteles "Rialto" de Ángel Gelaz, "Washington”, de Manuel Leyva y de A. Menéndez ubicados en la Plaza de la Revolución, en "Las Columnatas" situado en Saco y Estrada Palma, en el Hotel "Telégrafo" de Antonio Campos, en Saco no. 47, en el Hotel Central de Gastón Blanco y en el Hotel "Europa" de Feliciano Nuñez emplazado en Saco y Pio Rosado, en esta última se ubicó en Café con Billar de Luis Pavón.

${ }^{23}$ En 1919 se funda en Veguita la Sociedad de Instrucción y Recreo "Nueva Era"; en 1926 para los mismos fines se crea el Círculo Guisa y en 1930 el Horno Unión Club. Con propósitos políticos, en el primer barrio citado surge, en 1920, la Juventud Liberal; en 1922 la logia masónica, con el nombre homónimo al lugar donde se creó y en 1933 existen noticias de un Círculo Veguita, quizás forjado desde el seno de Nueva Era, o pudo haber sido una nueva sociedad. AHPSC.: FGP, leg. 2626, exp. 16, leg. 2684, exp. 1, leg. 2669, exp. 4 y leg. 2709, exp. 5. 


\section{Prácticas de sociabilidad en la modernización de Bayamo}

granjerías $^{24}$ con sede en la Plaza de la Revolución y en las inmediaciones de la Iglesia "La Luz".

Junto a ello se percibieron los influjos del béisbol como signo modernizador. Por los años de la década de 1910 se observa la preocupación de la prensa por la escasa práctica de esa forma de ocio y la necesidad de formar clubes para la reanimación de la vida citadina. En este lapso no es casual la creación del Bayamo Baseball Club, el Club Ciclista y por la década del 20 del Bayamo F.C. propiciando el auge de torneos de béisbol, bicicleta y fútbol. El incentivo de esta moda tenían otra finalidad: contrarrestar las usuales peleas de gallos por considerarlas bárbaras para la época, sinónimo de un modelo "arcaico y medieval" identificado con España. Su eliminación presuponía la entronización de otro similar a "lo imaginado como civilizatorio", o sea, la sociedad norteamericana, "el paradigma del futuro". ${ }^{25}$ Estos rejuegos mostraban las encrucijadas de la modernidad en los inicios del siglo $\mathrm{XX}$.

A la par de las motivaciones por el deporte aconteció la cotidianeidad en los salones-teatro como el Oriente, Bayamo, Figueredo y César. Los mismos se perfilaron como circuitos para compartir e intercambiar ideas y gustos estéticos, mostrándose una notable diferencia respecto al período anterior donde no existían. También se estrenaron comedias de las casas teatrales europeas como la Ambrosio, de Turín, y la de los Señores Casado, de España, se ofrecieron temporadas de espectáculos circenses con las compañías "Santos y Artigas” y "Canarias", amén de otros certámenes y conciertos, incluso en las propias instituciones recreativas. Estos recintos pusieron a los bayameses en contacto con las producciones del mundo europeo y norteamericano.

La insistencia de los bayameses en el fomento de relaciones sociales tuvo un punto significativo en el reforzamiento de la sociedad civil, alentado por el progreso de la fundación de asociaciones. Así al iniciar el siglo XX aparecerán nuevas tipologías en el tejido asociativo bayamés que iban más allá de los ya conocidos fines de recreo, instrucción y socorro mutuo, predominantes al finalizar el siglo XIX. Se inscribirán entonces instituciones con propósitos comerciales, agrarios, masónicos y obreros, ampliándose la cifra de seis, entre 1880 y 1898, hasta diecisiete al cierre de 1910. Luego hacia la década del 1920-1930 una vez integradas sociedades de corte espírita, político, deportivo, cooperativo, cívico, profesional, patriótico y cultural se alcanzó el número de ciento dieciséis. Con ese aumento cuantitativo se puede declarar una fase de "boom asociativo local", sobre la base de las asociaciones inscritas, lo cual no desestima la posible existencia de otras sociedades que evadían la legalidad o se encontraban en fase de gestación y aún no habían sido aceptadas por el Negociado de Asociaciones del gobierno

\footnotetext{
24 Así se denominó a los dulces tradicionales bayameses: rosquitas, matahambres, roscablanda, ciruelas borrachas y otros alimentos como longanizas, chorizos. Las ventas realizadas durante la festividad de "Navidad y Reyes" estaban sujetas a tarifas normadas por el Ayuntamiento.

25 Para ampliar véase: Pablo Riaño San Marful: Gallos y Toros en Cuba. La Habana, Fundación Fernando Ortiz, 2002.
} 


\section{Dayami Rodríguez López}

provincial de Oriente.

De modo general, es visible una diversidad asociativa en la ciudad en consonancia con necesidades propias de la región en el orden de la instrucción, de la moral, del avance científico y el religioso, razón de la preponderancia de las de corte espiritista. Por otro lado, se evidencia un incremento de las de los obreros como sinónimo de la organización y auge de esta nueva clase, con ansias de superarse y defender sus intereses. Tal acontecer tuvo su correlato en los espacios de ocio donde los bayameses buscaron sustento cultural a la par del goce y progreso personal.

Entre esos recintos para el ocio se ubican las sociedades recreativas, caracterizadas como un espacio con la capacidad para propiciar distracción, actividad lúdica, instrucción, práctica deportiva y en algunos casos servicios benéficos. La diversidad de sus funciones la ubica como un campo complejo y dinámico en el área de la sociabilidad en tanto su devenir expresa las marcadas diferenciaciones sociales y contradicciones del proyecto modernizador.

\section{Los intersticios de la modernidad: una mirada desde las sociedades recreativas 1899-1930}

El incremento de las instituciones recreativas en Bayamo no estuvo alejado de la realidad del resto de la zona oriental, donde se percibe un aumento acelerado de las mismas. Entre las razones de dicho incremento estuvo el diseño de una arquitectura institucional que se prestaba para evadir las censuras del Gobierno provincial, pues ese tipo de asociación al ser instauradas con una finalidad más bien amplia, explícitamente socio-cultural y con propósitos de índole universal, quedaban mejor dispuestas para disimular otras intenciones como las de naturaleza política, aun cuando se fundaron algunas con explícitas declaraciones de sus deseos de conjugar lo recreativo con lo político. Además, de ello los beneficios brindados a los asociados, a saber, el acceso a la instrucción y al disfrute mediante la práctica de la lectura, el intercambio de ideas y la actividad lúdica constituyó un atractivo.

El "diseño universal" de esos sitios tuvo un alcance amplio y se asoció a una pluralidad de objetivos que implicaban la práctica de juegos no prohibidos, la realización de bailes y excursiones, acceso a instrucción mediante la creación de aulas, bibliotecas, salas de lecturas, la contratación de profesores, así como las suscripciones a periódicos y revistas para estar actualizados en materia de opinión. También se destacan sus acercamientos a la creación artístico-literaria mediante el auspicio de secciones de declamación, música, teatro, veladas literarias, donaciones para obras de artes, exposiciones de pintura, presentaciones de solistas y agrupaciones musicales, homenajes a intelectuales y artistas.

En muchos casos los deseos de conceder nuevos beneficios a sus asociados, condujeron a readecuaciones de los propósitos sociales de estas cofradías, entre 
ellos, la inclusión de la asistencia sanitaria para lo cual reglamentaron la contrata de servicios médicos, crearon sanatorios y brindaron socorro ante la muerte de socios y familiares. Al mismo tiempo facilitaron la práctica deportiva al fundar salas de esgrima y gimnasia y se insertaron a través de sus miembros en torneos locales de ajedrez, fútbol y béisbol.

Esta lista de acciones, algunas declaradas de forma ostensible, adquiere mayor significación si se contrastan con otras no explícitas en los reglamentos corporativos, los cuales visibilizan las intenciones ocultas del juego institucional. Lo no declarado transita por aspectos tales como los llamados "mitos apoliticistas"; ${ }^{26}$ así por ejemplo, tras el reconocimiento de la mayor parte de estas asociaciones como imparciales se hizo habitual la conexión con políticos locales y nacionales, de hecho muchos de sus miembros fueron activos en la política, defendieron tendencias partidistas o se pronunciaron ante problemas de la vida pública local y del país. Tal involucramiento estuvo no pocas veces atado al uso de la historia como fuente de legitimidad, para ello se procuró preservar la memoria histórica mediante la constante rememoración de fechas importantes, las donaciones para homenajear a figuras representativas de la historia nacional, así como en la organización de conferencias o veladas y la participación en actos públicos.

De igual modo, muchas de las sociedades recreativas mantuvieron posiciones conservadoras ante la cuestión de género, pues las mujeres solo podían asistir en condición de esposas e hijas de los señores socios y por tanto carecían de poder en las decisiones concernientes a la institución, lo que no era óbice para usar la belleza y el talento femenino como atractivo para la coordinación y realce de las actividades. Por otra parte, al compás de la exigencia de poseer un sitio estable para la congregación y el contacto entre sus afiliados, dichas entidades realizaron transformaciones en el ámbito constructivo y en la decoración de sus respectivas sedes, guiadas por cierto afán de refinamiento, procurando sobresalir ante el resto de sus homólogas. Mientras tanto, aumentaban las exigencias para asistir a sus salones sociales y se trazaban pautas de "buena conducta" que desdecían el carácter democrático proclamado en los reglamentos fundacionales.

En el plano de las vinculaciones internas, fomentaron el desarrollo y la diferenciación de ciertas elites a través de las estrategias asumidas para la admisión de socios, las erogaciones sociales exigidas, así como los requisitos demandados para pertenecer a la directiva de las mismas; a ello se unía el culto continuado a los socios fundadores. Estas relaciones estuvieron mediadas por la conformación de redes de contacto entre familias distinguidas, amigos, políticos, comerciantes, intelectuales y artistas, desconectados, en apariencia, de las identidades políticas y los intereses económicos. Por tal razón la comprensión del verdadero cosmos de sociabilidad vivido en estas instituciones de ocio, pasa por el

\footnotetext{
${ }^{26}$ Este término es utilizado por el historiador Carlos del Toro quién analiza la cuestión para el caso de las instituciones de las elites habaneras. La alta burguesía cubana 1920-1958. La Habana, Editorial de Ciencias Sociales, 2011, 2da edición, pp 72-91.
} 


\section{Dayami Rodríguez López}

análisis de la correspondencia entre sus fines manifiestos, aquellos no declarados y su actividad cotidiana.

Desde estos presupuestos se pautaron las relaciones de las diferentes clases, sectores y capas sociales en las instituciones recreativas de Bayamo. Las elites blancas cubanas y españolas, integrada por hacendados -esencialmente ganaderos-, algunos profesionales y comerciantes, se reunieron en el Liceo de Bayamo y la Colonia Española, sitios con estrictos límites para los sectores populares, compuestos por artesanos, trabajadores urbanos, jornaleros y vendedores, agrupados en La Igualdad (1903), Bayamo Social (1921), el Círculo Porvenir (1923) y Los Invencibles (1926).

En consonancia con la composición institucional, las necesidades e intereses de los socios se advirtió la complejidad de ámbito de la sociabilidad formal, ya fuera por lo referido a la variedad de denominaciones, a saber, círculos, centros, asociación, sociedades o por las redefiniciones que debieron realizar a sus objetivos sociales en busca de ofrecer mayores ventajas a sus beneficiarios, motivar el interés en aquellos alejados de las asociaciones y a la vez mantener créditos distintivos en el espectro social bayamés.

Las sociedades recreativas evidenciaron las contradicciones de la construcción de la modernidad en Bayamo. La concepción de su diseño como garantes de la satisfacción de necesidades instructivas, recreativas y lúdicas a sus socios y del confort de espacio físico donde se reunían, para alejarlos de los bares y cafés, ?vistos como sinónimo de amoralidad e incivilización?, a la vez llevaba implícito un acentuado exclusivismo. Este último quedó al descubierto en su quehacer cotidiano y obedeció a la tendencia de este tipo de instituciones a agrupar personas de similares posiciones de clase, a su declaratoria como centros eminentemente masculinos y por restringir el acceso a los no asociados.

Las relaciones establecidas entre los asociados, patentizaron los laberintos de la vida institucional, al establecer complejas conductas derivadas del ejercicio del poder. De ello resultaron las atribuciones especiales de los socios fundadores para integrar las juntas directivas, conducentes a la articulación y reafirmación de una elite al interior de las instituciones. De hecho se establecía una tácita correlación entre la magnitud de capitales económicos- culturales detentados y las prebendas obtenidas en el seno de la institución. Estos sitios fueron paradójicos, pues legitimaron posicionamientos sociales y diferenciaciones a contrapelo de una política abarcadora, ya que precisaban de la cantidad de integrantes para sobrevivir. Por tanto las sociedades recreativas nunca llegaron a ser homogéneas, a raíz de las preponderancias y distinciones alcanzadas por algunos socios sobre otros.

Desde tal fundamento, animaron a la elite local a realizar un uso doblemente agradable del ocio, pues la inversión de ciertas sumas de dinero y de una parte de su tiempo libre en asistir a las mismas le otorgaron significación, reconocimiento personal y un incremento de sus capitales simbólicos, con los consecuentes beneficios para sus negocios, la vida pública y política, sin obviar la diversión. 
Debido a esos procederes las instituciones "debieron ser" -pero no siempre fueron-, escuelas de valores cívicos y virtudes personales, estímulos al compañerismo, la fraternidad y el espíritu democrático. En ese fin amparaban el constante incentivo para lograr nuevos afiliados y fomentar una comunidad de hombres amantes de la civilización y el progreso. Sin embargo, hubo un recorte del espacio recreativo, en detrimento del ideal de fraternidad y solidaridad propugnado por dichas colectividades, cuando sancionaban la división clasista, creaban limitaciones para los inscritos y excluían a los no asociados.

Siguiendo este camino las instituciones para "negros y mulatos" reprodujeron no pocas veces las prácticas de los círculos burgueses, debido a su tinte exclusivista, pues no todos los de ese grupo racial podían ingresar a las mismas. Muchas de sus reglamentaciones, aun cuando aspiraban al progreso y la educación colectivos, las convirtieron en centros discriminadores en sí mismos, a pesar de la subalternidad que muchas veces estaba contenida en estas entidades, dada su condición racial e incluso económica.

Otro de los elementos distintivos de los centros recreativos de Bayamo en sus nexos con la modernización, fue su percepción renovadora para constituir y mantener el espacio recreativo y su respectiva funcionalidad. Dicha concepción apostó por la búsqueda de comodidades y de seguridad para el acto de esparcimiento, con el fin de mantener a los beneficiarios atraídos por la necesidad de asistir al sitio recreativo. Por tal motivo no escatimaron recursos en la construcción y readecuación de las casas sociales, en correlación con sus propósitos y la búsqueda de confort en los inmuebles, suceso que a la vez concedió valores ambientales y arquitectónicos a la ciudad.

Finalmente la proyección de las instituciones se vio influida por las intenciones de sus protagonistas de lograr beneficios personales a través del ámbito colectivo de actuación. No obstante, lograron irradiar una imagen distinta de la ciudad, a partir de las actividades preparadas; las redes establecidas con sus homólogas y los contactos con renombradas personalidades locales y nacionales, lo cual a la vez les permitió insertarse en el debate de la opinión pública. En este sentido las reseñas sobre las actividades sociales, los elogios a las directivas y socios constituyeron parte importante del discurso de la prensa en la configuración de las instituciones como sitios "diferentes" del resto de la sociedad global.

\section{A manera de cierre...}

Registrar la evolución del proceso modernizador en el caso de Bayamo presupuso tomar en consideración disímiles factores, entre los cuales se resalta la evolución del ámbito de las expresiones de sociabilidad. Esta dinámica de relaciones sociales, recurrente desde el siglo XIX sentó pautas para la expansión y formalización acontecida a partir del 1900, lo cual se revirtió en la apertura hacia 


\section{Dayami Rodríguez López}

nuevas formas asociativas, estrechamente ligadas a las condiciones histórico concretas de la ciudad. De tal suerte los espacios para la sociabilidad estuvieron entre los principales recursos para los ciudadanos legitimarse en el medio social donde se desenvolvían y mostrar gustos, iniciativas, motivaciones, capacidades organizativas, así como hábitos de comportamiento y consumo.

La ampliación del tejido asociativo bayamés y sus mutaciones en el orden cualitativo marchaban a tono con la modernización de la ciudad pues de apenas tres asociaciones existentes al nacer el siglo XX, se experimentó un crecimiento en más de un centenar de entidades, todas ellas con finalidades distintas y bajo las cuales se agruparon disímiles segmentos de la vecindad bayamesa. De hecho la red institucional no constituyó el mero reflejo de avances económicos tangibles como pudieran ser el despliegue de una infraestructura vial y de comunicaciones, así como el nacimiento o expansión de determinados servicios colectivos y la modificación del entorno físico. Los ámbitos de sociabilidad y especialmente las asociaciones fueron parte indisoluble de ese otro lado volitivo y creador del proceso modernizador bayamés que en muchos casos antecedió y contribuyó a las transformaciones materiales del territorio.

Más allá de las tipologías a las que pudieran adherirse, la mayoría de las instituciones sociales de Bayamo fueron nichos de conocimiento donde se debatieron asuntos de interés histórico, educativo y socio-cultural al tiempo que ofrecían a la ciudad mejoras en el orden arquitectónico y urbanístico y contribuían a renovar el entorno a través de donaciones para diferentes obras. Estos resultados le posibilitaron a la localidad un reconocimiento y visibilidad en la Nación desde lo concerniente a la vida asociativa.

Al margen de las contribuciones y los beneficios colaterales tributados por las sociedades recreativas a la urbe bayamesa, su organización bajo parámetros clasistas, raciales y de género las hizo reproducir y amplificar a escala micro las diferencias con el resto social y con ello acentuar las fisuras del proyecto modernizador, lo cual supuso retos para la integración local, regional y aun nacional en la histórica ciudad del Oriente de Cuba. 